\title{
Probability Analysis of Exchange Rate Target Zones
}

\author{
Huimin Zhao ${ }^{1}$, Fuzhou Gong ${ }^{2}$, Fangping Peng ${ }^{1} \&$ Qin Liu ${ }^{3}$ \\ ${ }^{1}$ School of Business, Sun Yat-sen University, Guangzhou, China \\ ${ }^{2}$ Academy of Mathematics and System Sciences, Chinese Academy of Sciences, Beijing, China \\ ${ }^{3}$ Mathengine Capital, Beijing, China \\ Correspondence: Huimin Zhao, School of Business, Sun Yat-sen University, Guangzhou, China. Tel: \\ 86-20-8411-2637. E-mail: zhaohm@gmail.com
}

Received: November 25, 2013

doi:10.5430/ijfr.v5n1p29
Accepted: December 16, $2013 \quad$ Online Published: January 10, 2014

URL: http://dx.doi.org/10.5430/ijfr.v5n1p29

We acknowledge helpful comments from Minping Qian, Guofu Wu and seminar participants at the Institute of Applied Mathematics, Chinese Academy of Sciences. Huimin Zhao has been supported by the Fundamental Research Funds for the Central Universities (Project No. 1209022) and National Natural Science Foundation of China (Project No. 71303265).

\begin{abstract}
The objective of this paper is to show quantitative results for the exchange rate target zones in a small open economy. We develop a stochastic model for exchange rates under the equilibrium in goods and money markets based on a variation of Dornbusch (1976)'s model, incorporating several kinds of macroeconomic shocks and a noneconomic factor ignored by literature. Using the theory of stochastic differential equation (SDE) in probability theory, we calculate the probabilities that the nominal exchange rates reach the boundaries of the target zones for the first time, and the mean time that the nominal exchange rates remain in the target zones. Furthermore, using our explicit expressions of the fundamental factor and the defnite relationships between the variables, we analyze the effects on the probabilities from macroeconomic and non-economic factors, such as the elasticity of the premium rate of exchange rates, the fundamental factor, and the volatilities of the shocks.
\end{abstract}

Keywords: exchange rate, target zone, probability analysis

\section{Introduction}

There is a significant body of literature studying the exchange rate target zones through a range of different methods. Dornbusch (1976) develop a simple macroeconomic framework for the study of exchange rate movements in a small open economy. Kleig (1990) introduce the shocks of aggregate demand of goods and money supply in a classical model. Soon after, Krugman (1991) initiate the stochastic model of target zone exchange rates and analyzed the effects on the behavior of the nominal exchange rate from the given boundaries of the target zones. Following this idea, a large amount of research on target zones has been reported in theoretical papers such as those by Bauer (2000), by Larsen (2007), and by Bauer, Grauwe, and Reitz (2008), as well as in econometric papers, for a short review, see Christensen, Lando, and Miltersen (1998); De Jong, Drost, and Werker (2001); or Portugal Duarte et al. (2011). However, as an important issue which the governments care about, the stabilization properties of the exchange rate target zones has maintained quantitatively unanswered.

Bertola and Caballero (1992) extend Krugman's (1991) model by replacing the fundamental with the money supply in order to study the stabilization of exchange rates in target zones. Due to their limited assumptions for the fundamental factors of the economy, they cannot achieve quantitative results of the effects on the target zones. Allowing for transitory unemployment in a small open economy, several kinds of shocks of demand and supply and intramarginal interventions, Beetsma, and Van der Ploeg (1998) build a dynamic model based on a simplification of Dornbusch's (1976) model. They prove that the rational expectations equilibrium must be a saddle path solution of the economy if the nominal exchange rates always stay in the target zones. To incorporate the possibility of price inertia, Miller and Weller (1991) build the sticky price target-zone model, in which mean reversion in the exchange rate is generated by the price adjustment process, so there is no need to make assumptions about policy actions. To 
fit the data better, Bertola and Svensson (1993) consider stochastic devaluation risk in target-zone models to obtain a rich data-generation structure. Tronzano, Psaradakis and Sola (2003) analyze the 1992 - 1993 exchange rate crisis of the ERM based on a Markov switching model, and argue that transition probabilities are time-varying depending on different driving macroeconomic variables. Ito and Yabu (2007) and Lee (2011) build a non-linear exchange rate model which ignores the assumption of Krugman's (1991) model that the money supply is only used to maintain the target zone. Bauer et al. (2009) derive a model using a heterogeneous agent structure. In their model, the fundamental factor of the economy is driven by a nonlinear stochastic differential equation (SDE). Data generated from it are more consistent with exchange rate behavior. Beladi and Chakrabarti (2012) include the lagged fundamentals in exchange rate regressions and find that goodness of fit is improved.

In this paper, our model incorporates a non-economic factor with its shock and several shocks of macroeconomic variables ignored by literature. We build a dynamic model of exchange rates based on a variation of Dornbusch's (1976) model. In our model, the fundamental factor, the elasticity of premium rate of exchange rates, and the standard deviation of shock of exchange rates are all explicitly expressed. We also establish the definite relationships between the macroeconomic variables and exchange rates.

Even though the economy authorities hope to keep the exchange rates maintain the target zones to stimulate the international trade and investment, in practice, in the long run, the exchange rates cannot always stay in the target zones. It will be enough good to maintain the exchange rates in the target zones for a given time period. Therefore, it is more meaningful to investigate the probabilities that the exchange rates reach the boundaries of the target zones for the first time, the average time in which the exchange rates remain in the target zones. Using the theory of SDE in probability theory, we can estimate the probabilities and the average time. Furthermore, based on the explicit expressions of the economic factors we derived, we can analyze the effects on exchange rate target zones from these factors.

The rest of the paper is organized as follows. Section 2 presents our macroeconomic dynamic model in a small open economy. Section 3 establishes the explicit relationships between exchange rates and several macroeconomic variables in the model. We compare our model with Krugman's (1991) model in Section 4, as well as discussing the probabilities and the average time that the exchange rates maintain in the target zone. The paper is concluded in Section 5.

\section{The Dynamic Macroeconomic Model}

\subsection{Equilibrium in the Good Market}

Our model is built in a small open economy, which is an economy that participates in international trade, but is small enough compared to its trading partners. The economic policies of this kind of economy do not alter world product prices, interest rates, or incomes. Thus, the countries with small open economies are price takers.

In a small open economy, in the good market, the aggregate demand $Y_{t}$ satisfies the IS curve:

$$
\mathrm{Y}_{\mathrm{t}}=L\left(\mathrm{Q}_{\mathrm{t}} ; Y_{t}^{*} ; \mathrm{r}_{\mathrm{t}}\right) \text {; }
$$

where $Q_{t}$ is the real exchange rate at time $t$ and can be represented by the nominal spot exchange rate $S_{t}$ as the following:

$$
\mathrm{Q}_{\mathrm{t}}=\frac{P_{t}^{*}}{P_{\mathrm{t}} \mathrm{S}_{\mathrm{t}}}
$$

where $P_{t}^{*}$ is the foreign price level, $P_{\mathrm{t}}$ is the domestic price level, $Y_{t}^{*}$ is the foreign output level, and $\mathrm{r}_{\mathrm{t}}$ is the domestic real interest rate.

When the goods market is in equilibrium, which means that market is clear, following Dornbusch (1976) there is a linear relationship between the logarithms of these economic variables:

$$
\mathrm{y}_{\mathrm{t}}=\alpha\left(\mathrm{s}_{\mathrm{t}}+p_{t}^{*}-p_{\mathrm{t}}\right)+\beta y_{t}^{*}-\tilde{\delta} \mathrm{r}_{\mathrm{t}} .
$$

where $p_{\mathrm{t}}, \mathrm{y}_{\mathrm{t}}, \mathrm{s}_{\mathrm{t}}$ and $y_{t}^{*}$ are the logarithms of $P, \mathrm{Y}_{\mathrm{t}}, \mathrm{S}_{\mathrm{t}}$ and $Y_{t}^{*}$ respectively, and $\alpha>0, \beta>0, \tilde{\delta}>0$.

In the real economy, unexpected shocks exist in the short run. Without loss of generality, we suppose that there is a shock $\varepsilon_{y, t}$ at time $\mathrm{t}$ which has an effect on the equilibrium aggregate demand, that is

$$
\mathrm{y}_{\mathrm{t}}=\alpha\left(\mathrm{s}_{\mathrm{t}}+p_{t}^{*}-p_{\mathrm{t}}\right)+\beta y_{t}^{*}-\tilde{\delta} \mathrm{r}_{\mathrm{t}}+\varepsilon_{y, t}
$$

where $E\left(\varepsilon_{y, t}\right)=0$, and $\operatorname{var}\left(\varepsilon_{y, t}\right)=\sigma_{y}^{2}$. 


\subsection{Equilibrium in the Money Market}

In the money market, the real demand for money $M_{t}^{d} / P_{\mathrm{t}}$ at time $t$ is a function of the real income $\mathrm{Y}_{\mathrm{t}}$ and the nominal interest rate $i_{t}$. The nominal interest rate $i_{t}$ is the opportunity cost of the money a person or entity holds. So if the nominal interest rate increases, the money in hand will decrease because of the increased opportunity cost of holding money in hand. Then the real demand for money $M_{t}^{d} / P_{\mathrm{t}}$ is a decreasing function of the nominal interest rate $\mathrm{i}_{\mathrm{t}}$. On the other hand, if the real income $\mathrm{Y}_{\mathrm{t}}$ increases, the real demand for money $M_{t}^{d} / P_{\mathrm{t}}$ will also increase to match the much greater consumption requirement. It means that the real demand for money $M_{t}^{d} / P_{\mathrm{t}}$ is an increasing function of $\mathrm{Y}_{\mathrm{t}}$.

Considering the shock $\varepsilon_{m, t}$ on the demand of the money, we have the following relation:

$$
m_{t}^{d}-p_{\mathrm{t}}=\varnothing \mathrm{y}_{\mathrm{t}}-\lambda \mathrm{i}_{\mathrm{t}}+\varepsilon_{m, t} .
$$

where $E\left(\varepsilon_{m, t}\right)=0, \operatorname{var}\left(\varepsilon_{m, t}\right)=\sigma_{m}^{2}, \emptyset>0, \lambda>0$, and $m_{t}^{d}$ is the logarithm of the nominal demand for money $M_{t}^{d}$.

\subsection{The Real Interest Rate}

The relation between the real and nominal interest rates is the following:

$$
\mathrm{r}_{\mathrm{t}}=\mathrm{i}_{\mathrm{t}}-\mathrm{E}_{\mathrm{t}} d \mathrm{p}_{\mathrm{t}} / d t
$$

Where $\mathrm{E}_{\mathrm{t}} d \mathrm{p}_{\mathrm{t}} / d t$ is the rate of inflation expectation at time $t$.

\subsection{The Non-Economic Factors}

Most of the models we mention explain the movement of exchange rates by economic factors, such as money supply, aggregate output level, inflation, unemployment etc.. But non-economic factors play an increasingly important role in the real world. For example, wars, the policies of whichever political party happens to be in office, natural disasters, generational shift, change in the makeup of the family, anything that is purely political, natural, or sociocultural. These non-economic factors may induce the deviation from the purchasing power parity (PPP) especially in the short run. In some cases non-economic factors may make exchange rates overreaction or defer the adjustment process to reach equilibrium.

So we introduce the non-economic factor $f_{t}$ in our model. Suppose that the non-economic factor $f_{t}$ satisfies the one-order autoregressive process represented by an SDE as follows:

$$
d \mathrm{f}_{\mathrm{t}}=\psi_{f} \mathrm{f}_{\mathrm{t}} d t+\sigma_{f, t} d z_{f, t},
$$

where $d z_{f, t} \sim \operatorname{IN}(0, d t), z_{f, t}$ is the standard Brownian Motion, $\psi_{f}>0$ is the mean-reversion parameter of $\mathrm{f}_{\mathrm{t}}$, $\sigma_{f, t}>0$ is the instantaneous deviation of the non-economic factor $f_{t}$ and $f_{0}$ is initially given.

Hence, the equation (5) can be given by another expression:

So $\mathrm{E}_{\mathrm{t}} \mathrm{f}_{\mathrm{t}}=\mathrm{e}^{-\psi_{f} \mathrm{t}_{0}}$.

$$
\mathrm{f}_{\mathrm{t}}=\mathrm{e}^{-\psi_{f} \mathrm{t}}\left(\mathrm{f}_{0}+\int_{0}^{t} \mathrm{e}^{-\psi_{f} \mathrm{~s}} \sigma_{f, s} d z_{f, s}\right) .
$$

\subsection{Uncovered Interest Parity Condition}

As Dornbusch (1976) note, if the monetary approach is assumed to be the perfect sub-stitutability between domestic and foreign bonds, it is indifferent for investors to hold whatever assets. Then the supply of bonds becomes irrelevant. Therefore, if the domestic currency is expected to depreciate, the return of the assets denominated by domestic currency will be greater than that of the assets denominated by the foreign currency.

The depreciation of the currency can be expressed as the difference between the interest rates:

$$
\mathrm{i}_{\mathrm{t}}=i_{t}^{*}+\mathrm{E}_{\mathrm{t}} d \mathrm{p}_{\mathrm{t}} / d t,
$$

where $\mathrm{E}_{\mathrm{t}} d \mathrm{p}_{\mathrm{t}} / d t$ is the rate of depreciation expectation at time $t$, and $i_{t}^{*}$ is the foreign nominal interest rate.

Basen on Dornbusch (1976), in equilibrium, the expected depreciation of currency is usually a linear function of the difference between the nominal exchange rate $s_{t}$ and the real exchange rate $\overline{s_{t}}$. That is,

$$
\mathrm{E}_{\mathrm{t}} d \mathrm{p}_{\mathrm{t}} / d t=\theta\left(\overline{\mathrm{s}_{\mathrm{t}}}-\mathrm{s}_{\mathrm{t}}\right)
$$

where $\theta>0$ is a parameter.

When one investor invests in foreign assets, the opportunity cost $\mathrm{C}$ of this investment is:

$$
\mathrm{C}=\mathrm{A}\left(1+\mathrm{i}_{\mathrm{t}}\right) \text {, }
$$

and the return $R$ from the foreign investment is: 


$$
R=A\left(1+i_{t}^{*}\right) F_{\mathrm{t}} / \mathrm{S}_{\mathrm{t}}
$$

where $F_{\mathrm{t}}$ is the forward exchange rate.

So we get the net return $\hat{\pi}$ :

$$
\hat{\pi}=A\left(1+i_{t}^{*}\right) F_{\mathrm{t}} / \mathrm{S}_{\mathrm{t}}-\mathrm{A}\left(1+\mathrm{i}_{\mathrm{t}}\right) .
$$

Define $\widetilde{\mathrm{S}_{\mathrm{t}}}$ as $\widetilde{\mathrm{S}_{\mathrm{t}}}=\left(F_{\mathrm{t}}-\mathrm{S}_{\mathrm{t}}\right) / \mathrm{S}_{\mathrm{t}}=F_{\mathrm{t}} / \mathrm{S}_{\mathrm{t}}-1$,

then we have the following relationship:

$$
\left(1+i_{t}^{*}\right)\left(\widetilde{\mathrm{S}_{\mathrm{t}}}+1\right)=1+\mathrm{i}_{\mathrm{t}}+A\left(d \mathrm{i}_{\mathrm{t}} / d A\right) .
$$

In practice, $\widetilde{\mathrm{S}_{\mathrm{t}}}$ is far smaller than $i_{t}^{*}$, then we take $\widetilde{\mathrm{S}_{\mathrm{t}}} \cdot i_{t}^{*} \approx 0$, then

$$
\widetilde{\mathrm{S}_{\mathrm{t}}}=A\left(d \mathrm{i}_{\mathrm{t}} / d A\right)+\mathrm{i}_{\mathrm{t}}-i_{t}^{*} \text {. }
$$

Dornbusch (1976) assume that the flow of capital is perfectly free. But in the real world, it is impossible. Therefore, we introduce the supply elasticity of the arbitrage capital $\widetilde{\mathrm{E}_{\mathrm{s}}}$ as follows:

$$
\widetilde{\mathrm{E}_{\mathrm{s}}}=(d A / A) /\left(d \mathrm{i}_{\mathrm{t}} / \mathrm{i}_{\mathrm{t}}\right)
$$

then we have

$$
\widetilde{\mathrm{S}_{\mathrm{t}}}=\left(1+\frac{1}{\widetilde{\mathrm{E}_{\mathrm{s}}}}\right) \mathrm{i}_{\mathrm{t}}-i_{t}^{*}
$$

Note that, $\widetilde{\mathrm{S}_{\mathrm{t}}}$ is also the expectation change of exchange rates at time $t\left(\mathrm{E}_{\mathrm{t}} d s_{\mathrm{t}} / d t\right)$. We can get the uncovered interest rate parity condition along with the shock of the non-economical factor as follows:

$$
\mathrm{E}_{\mathrm{t}} d s_{\mathrm{t}}=\left[\left(1+\frac{1}{\widetilde{\mathrm{E}_{\mathrm{s}}}}\right) \mathrm{i}_{\mathrm{t}}-i_{t}^{*}\right] d t+d \mathrm{f}_{\mathrm{t}} .
$$

If $\frac{1}{\widetilde{\mathrm{E}_{\mathrm{s}}}} \approx 0$ and $\mathrm{E}_{\mathrm{t}} d f=0_{\mathrm{t}}$, then formula (1) in Dornbusch (1976) is our special case.

\subsection{Price Adjustment Process}

The Phillips-Curve describes the dynamic relationship between the supply and demand for labor and the inflation of the economy. Considering the shocks on the nominal wage and the non-economic factor, the price adjustment process can be given by the following partial differential equation (PDE):

$$
d \mathrm{p}_{\mathrm{t}}=\theta_{p}\left(\mathrm{y}_{\mathrm{t}}-y_{t}^{F}\right) d t+\sigma_{p, t} d z_{p, t}+\sigma_{f, t} d z_{f, t},
$$

where $z_{p, t}$ and $z_{f, t}$ are two independent standard Brownian motions representing the shocks of nominal wages and the non-economic factor respectively, $\sigma_{p, t}>0$ is the instantaneous standard deviation of price change, $\sigma_{f, t}>0$ is the instantaneous standard deviation of shock of the non-economic factor at time $t, y_{t}^{F}$ is the long-term mean of the logarithm of the aggregate income under the full-employment, and $\theta_{p}>0$ is the mean-reverting speed.

By taking the conditional expectation up to time $t$ for the above equation, we have

$$
\mathrm{E}_{\mathrm{t}} d \mathrm{p}_{\mathrm{t}} / d t=\theta_{p}\left(\mathrm{y}_{\mathrm{t}}-y_{t}^{F}\right),
$$

where Etdpt represents the inflation expectation at time $t$.

\subsection{The Shock of Aggregate Demand}

We suppose that the shock $\varepsilon_{y, t}$ of aggregate demand satisfies the following SDE:

$$
d \varepsilon_{y, t}=-\psi_{y} \varepsilon_{y, t} d t+\sigma_{y, t} d z_{y, t}
$$

where $d z_{y, t} \sim I N(0, d t), z_{y, t}$ is the standard Brownian motion, $\sigma_{y, t}>0$ is the instantaneous standard deviation of the shock of aggregate demand, $\psi_{y}$ is the mean-reversion parameter of $\varepsilon_{y, t}$, and $0<\psi_{y}<1 . \varepsilon_{y, 0}$ is fixed and denotes the shock of aggregate demand at the time $t=0$. Hence, $\varepsilon_{y, t}$ is an Ornstein-Unlenbeck process. In particular,

$$
\varepsilon_{y, t}=\mathrm{e}^{-\psi_{y} \mathrm{t}}\left(\varepsilon_{y, 0}+\int_{0}^{t} \mathrm{e}^{-\psi_{y} \mathrm{~s}} \sigma_{y, s} d z_{y, s}\right)
$$

Then $\mathrm{E}_{\mathrm{t}} \varepsilon_{y, t}=\mathrm{e}^{-\psi_{y} \mathrm{t}} \varepsilon_{y, 0}$. We do not assume that $\varepsilon_{y, 0}$ is zero, because the initial economy is not usually in equilibrium.

\subsection{The Shock of Money Demand}

We also suppose that the shock of money demand satisfies the following SDE:

$$
d \varepsilon_{m, t}=-\psi_{m} \varepsilon_{m, t} d t+\sigma_{m, t} d z_{m, t}
$$

where $d z_{m, t} \sim \operatorname{IN}(0, d t), z_{m, t}$ is the standard Brownian motion, $\psi_{m}$ is the mean-reversion parameter of $\varepsilon_{m, t}$ and 
$0<\psi_{m}<1$, and $\sigma_{m, t}>0$ is the instantaneous deviation of shock of money demand. $\varepsilon_{m, 0}$ is fixed and denotes the shock of money demand at the time $t=0$.

Solving the above SDE, we have

$$
\varepsilon_{m, t}=\mathrm{e}^{-\psi_{m} \mathrm{t}}\left(\varepsilon_{m, 0}+\int_{0}^{t} \mathrm{e}^{-\psi_{m} \mathrm{~s}} \sigma_{m, s} d z_{m, s}\right),
$$

So $\mathrm{E}_{\mathrm{t}} \varepsilon_{m, t}=\mathrm{e}^{-\psi_{m} \mathrm{t}} \varepsilon_{m, 0}$.

\subsection{The Demand Function}

According to Dornbusch (1976), the demand function for domestic products $y_{t}^{d}$ is determined by the relative prices of domestic products, interest rates, and real income. This relationship can be expressed as:

$$
y_{t}^{d}=u+\delta\left(\mathrm{s}_{\mathrm{t}}-\mathrm{p}_{\mathrm{t}}\right)+\gamma \mathrm{y}_{\mathrm{t}}-\sigma \mathrm{i}_{\mathrm{t}},
$$

Where $u$ is the constant, $\delta$ is the elasticity of relative prices, $\gamma$ is the income elasticity, $\sigma$ is the elasticity of interest rate, and $\delta>0, \gamma>0, \sigma>0$.

We define $\dot{p}_{t}$ as the rate of inflation expectation, that is,

$$
\dot{p}_{t} \equiv \mathrm{E}_{\mathrm{t}} d \mathrm{p}_{\mathrm{t}} / d t \text {. }
$$

Then $\dot{p}_{t}$ and the excess demands of products have the following relationship:

$$
\dot{p_{t}}=\pi\left(y_{t}^{d}-\mathrm{y}_{\mathrm{t}}\right)=\pi\left(u+\delta\left(\mathrm{s}_{\mathrm{t}}-\mathrm{p}_{\mathrm{t}}\right)+(\gamma-1) \mathrm{y}_{\mathrm{t}}-\sigma \mathrm{i}_{\mathrm{t}}\right),
$$

where $\pi>0$.

In equilibrium, all markets are clear, so we have the following equilibrium conditions:

$$
\dot{p}_{t}=0, i_{\mathrm{t}}=i_{t}^{*}, \mathrm{p}_{\mathrm{t}}=\overline{\mathrm{p}_{\mathrm{t}}}, \mathrm{s}_{\mathrm{t}}=\overline{\mathrm{s}_{\mathrm{t}}}, \mathrm{y}_{\mathrm{t}}=y_{t}^{F} \text {. }
$$

We get

$$
\overline{\mathrm{s}_{\mathrm{t}}}=\overline{\mathrm{p}_{\mathrm{t}}}+\frac{1}{\delta}\left[\sigma i_{t}^{*}+(1-\gamma) y_{t}^{F}-u\right]
$$

\section{The Dynamic Model of Exchange Rates}

To simplify our model, we present the following reasonable hypothesis:

(1) The money demand $m_{t}^{d}$, the foreign price level $p_{t}^{*}$, and the foreign output $y_{t}^{*}$ have no shocks, in the sense that, $m_{t}^{d}, p_{t}^{*}, y_{t}^{*}$ have no continuous martingale parts (see Revuz and Yor (1991)), and $d m_{t}^{d} / d t, \mathrm{~d} p_{t}^{*} / d t$, and $d p_{t}^{*} /$ dt exist.

(2) $s_{t}$ is always positive, that is, $s_{t}>0$, or equivalently, the nominal exchange rate $S_{t}>1$.

(3) The macroeconomic variables, $p_{t}, m_{t}^{d}, p_{t}^{*}$ and $y_{t}^{*}$ are exogenous variables for our model.

(4) The standard Brownian Motions $z_{f, t}, z_{y, t}, z_{p, t}$ and $z_{m, t}$ are independent each other.

Then, we have the following propositions:

Proposition 1. In equilibrium, the nominal exchange rate $\mathrm{s}_{\mathrm{t}}$ satisfies the following SDE:

$$
\mathrm{ds}_{\mathrm{t}}=\left(\mathrm{F}_{\mathrm{t}}+\rho \mathrm{s}_{\mathrm{t}}\right) d t+\hat{\sigma}_{\mathrm{t}} d z_{s, t}
$$

where $\mathrm{F}_{\mathrm{t}}$ is the fundamental in the economy, $\rho$ is the elasticity of the premium rate of exchange rates, $\hat{\sigma}_{\mathrm{t}}>0$ is the instantaneous standard deviation of $\mathrm{s}_{\mathrm{t}}$, and $z_{s, t}$ is the standard Brownian Motion. Furthermore,

$$
\begin{gathered}
\mathrm{F}_{\mathrm{t}}=\hat{\beta} \mathrm{p}_{\mathrm{t}}+\hat{\gamma} m_{t}^{d}+\hat{\theta} y_{t}^{*}+\hat{\lambda} p_{t}^{*}+\hat{\phi} u-\psi_{f} \mathrm{f}_{\mathrm{t}}+\hat{\psi}_{y} \mathrm{E}_{\mathrm{t}} \varepsilon_{y, t}+\hat{\psi}_{m} \mathrm{E}_{\mathrm{t}} \varepsilon_{m, t}, \\
\rho=\hat{\alpha}, \\
\hat{\sigma}_{\mathrm{t}}^{2}=\mathrm{E}_{\mathrm{t}}\left(\mathrm{ds}_{\mathrm{t}}\right)^{2} / d t=(\eta / \xi)^{2}\left(\sigma_{p, t}^{2}+\sigma_{f, t}^{2}\right)+(1+\pi \gamma \tilde{\delta})^{2} / \xi^{2} \sigma_{m, t}^{2}+(\phi / \xi)^{2} \sigma_{y, t}^{2},
\end{gathered}
$$

where

$$
\begin{gathered}
\mathrm{a}=1 /[\lambda(1-\pi \gamma \tilde{\delta}+\pi \delta)+\phi \tilde{\delta}(1+\pi \sigma)], \\
\hat{\alpha}=a \phi(\alpha+\pi \delta \tilde{\delta})\left[1 / \widetilde{\mathrm{E}_{\mathrm{s}}}+\pi \lambda(\gamma-1) / \phi-\pi \sigma\right]+\pi \delta \\
\left.\hat{\beta}=a[1-\pi \gamma \tilde{\delta}+\pi \delta-\phi(\alpha+\pi \delta \tilde{\delta})]\left[1 / \widetilde{\mathrm{E}_{\mathrm{s}}}+\pi \lambda(\gamma-1) / \phi-\pi \sigma\right]-[\pi \delta+(\gamma-1) / \phi)\right], \\
\hat{\gamma}=a(\pi \gamma \tilde{\delta}-\pi \tilde{\delta}-1)\left[1 / \widetilde{\mathrm{E}_{\mathrm{s}}}+\pi \lambda(\gamma-1) / \phi-\pi(\gamma-1) / \phi\right], \\
\hat{\lambda}=a \phi \alpha\left[1 / \widetilde{\mathrm{E}_{\mathrm{s}}}+\pi \lambda(\gamma-1) / \phi-\pi \sigma\right],
\end{gathered}
$$




$$
\begin{gathered}
\hat{\theta}=a \phi \beta\left[1 / \widetilde{\mathrm{E}_{\mathrm{s}}}+\pi \lambda(\gamma-1) / \phi-\pi \sigma\right]+\pi, \\
\hat{\phi}=a \phi \pi \tilde{\delta}\left[1 / \widetilde{\mathrm{E}_{\mathrm{s}}}+\pi \lambda(\gamma-1) / \phi-\pi \sigma\right]+\pi, \\
\hat{\psi}_{y}=a \phi\left[1 / \widetilde{\mathrm{E}_{\mathrm{s}}}+\pi \lambda(\gamma-1) / \phi-\pi \sigma\right], \\
\hat{\psi}_{m}=a(1-\pi \gamma \tilde{\delta}+\pi \tilde{\delta})\left[1 / \widetilde{\mathrm{E}_{\mathrm{s}}}+\pi \lambda(\gamma-1) / \phi-\pi \sigma\right]-\pi(\gamma-1) / \phi, \\
\xi=\phi(\alpha+\pi \delta \tilde{\delta})[1-a \lambda(1+\pi \gamma \tilde{\delta})+a \phi \tilde{\delta}(1+\pi \sigma)], \\
\eta=\phi(\alpha+\pi \delta \tilde{\delta})-1-\pi \gamma \tilde{\delta}+a[\lambda(1+\pi \gamma \tilde{\delta})+\phi \tilde{\delta}(1+\pi \sigma)][1-\pi \gamma \tilde{\delta}+\pi \tilde{\delta}-\phi(\alpha+\pi \delta \tilde{\delta})] .
\end{gathered}
$$

Proof. See Appendix A.

Proposition 2. In equilibrium, the aggregate demand $\mathrm{y}_{\mathrm{t}}$ has a following relation with other macroeconomic variables in our model:

$$
\mathrm{y}_{\mathrm{t}}=a_{1}^{y} \mathrm{~s}_{\mathrm{t}}+a_{2}^{y} \mathrm{p}_{\mathrm{t}}+a_{3}^{y} p_{t}^{*}+a_{4}^{y} y_{t}^{*}+a_{5}^{y} m_{t}^{d}+a_{6}^{y} \mathrm{E}_{\mathrm{t}} \varepsilon_{y, t}+a_{7}^{y} \mathrm{E}_{\mathrm{t}} \varepsilon_{m, t}+u^{y},
$$

where

$$
\begin{aligned}
& a_{1}^{y}=a \lambda(\alpha+\pi \delta \tilde{\delta}), \\
& a_{2}^{y}=-a[\lambda(\alpha+\pi \delta \tilde{\delta})+\tilde{\delta}(1+\pi \sigma) \text {, } \\
& a_{3}^{y}=a \lambda \alpha \text {, } \\
& a_{4}^{y}=a \lambda \beta, \\
& a_{5}^{y}=a \tilde{\delta}(1+\pi \sigma), \\
& a_{6}^{y}=a \lambda, \\
& a_{7}^{y}=-a \tilde{\delta}(1+\pi \sigma) \text {, } \\
& u^{y}=a \lambda \pi \tilde{\delta} u, \\
& \mathrm{r}_{\mathrm{t}}=\left[\left(\alpha-a_{1}^{y}\right) s_{t}-\left(\alpha+a_{2}^{y}\right) p_{t}-a_{5}^{y} m_{t}^{d}+\left(\alpha-a_{3}^{y}\right) p_{t}^{*}\right. \\
& \left.+\left(\beta-a_{4}^{y}\right) y_{t}^{*}+\left(1-a_{6}^{y}\right) E_{t} \varepsilon_{y, t}-a_{7}^{y} E_{t} \varepsilon_{m, t}-u^{y}\right] / \tilde{\delta}, \\
& \mathrm{i}_{\mathrm{t}}=b_{1}^{i} \mathrm{~s}_{\mathrm{t}}+b_{2}^{i} \mathrm{p}_{\mathrm{t}}+b_{3}^{i} m_{t}^{d}+b_{4}^{i} p_{t}^{*}+b_{5}^{i} y_{t}^{*}+b_{6}^{i} \mathrm{E}_{\mathrm{t}} \varepsilon_{y, t}+b_{7}^{i} \mathrm{E}_{\mathrm{t}} \varepsilon_{m, t}+u^{i} \text {, } \\
& \overline{\mathrm{s}_{\mathrm{t}}}=c_{1}^{s} \mathrm{~s}_{\mathrm{t}}+c_{2}^{s} \mathrm{p}_{\mathrm{t}}+c_{3}^{s} m_{t}^{d}+c_{4}^{s} p_{t}^{*}+c_{5}^{s} y_{t}^{*}+c_{6}^{s} \mathrm{E}_{\mathrm{t}} \varepsilon_{y, t}+c_{7}^{s} \mathrm{E}_{\mathrm{t}} \varepsilon_{m, t}+u^{s} \text {, } \\
& y_{t}^{F}=d_{1}^{F} \mathrm{~s}_{\mathrm{t}}+d_{2}^{F} \mathrm{p}_{\mathrm{t}}+d_{3}^{F} m_{t}^{d}+d_{4}^{F} p_{t}^{*}+d_{5}^{F} y_{t}^{*}+d_{6}^{F} \mathrm{E}_{\mathrm{t}} \varepsilon_{y, t}+d_{7}^{F} \mathrm{E}_{\mathrm{t}} \varepsilon_{m, t}+u^{F} \text {, } \\
& i_{t}^{*}=j_{1}^{*} \mathrm{~s}_{\mathrm{t}}+j_{2}^{*} \mathrm{p}_{\mathrm{t}}+j_{3}^{*} m_{t}^{d}+j_{4}^{*} p_{t}^{*}+j_{5}^{*} y_{t}^{*}+j_{6}^{*} \mathrm{E}_{\mathrm{t}} \varepsilon_{y, t}+j_{7}^{*} \mathrm{E}_{\mathrm{t}} \varepsilon_{m, t}+u^{*}, \\
& \overline{p_{\mathrm{t}}}=k_{1}^{p} \mathrm{~s}_{\mathrm{t}}+k_{2}^{p} \mathrm{p}_{\mathrm{t}}+k_{3}^{p} m_{t}^{d}+k_{4}^{p} p_{t}^{*}+k_{5}^{p} y_{t}^{*}+k_{6}^{p} \mathrm{E}_{\mathrm{t}} \varepsilon_{y, t}+k_{7}^{p} \mathrm{E}_{\mathrm{t}} \varepsilon_{m, t}+u^{p} \text {, }
\end{aligned}
$$

Where $\left(b_{i}^{x}\right)_{1 \leq i \leq 7}, \quad\left(c_{i}^{x}\right)_{1 \leq i \leq 7},\left(d_{i}^{x}\right)_{1 \leq i \leq 7}, \quad\left(j_{i}^{x}\right)_{1 \leq i \leq 7}, \quad\left(k_{i}^{x}\right)_{1 \leq i \leq 7}$, with $x$ replaced by the corresponding macroeconomic variables and $u^{i}, u^{s}, u^{F}, u^{*}$ and $u^{p}$ are all constants. Its expressions are given in Appendix $B$.

Proof. It can be proved by solving the linear equation system in Section 2 step by step.

\section{Probability Analysis of Exchange Rate Target Zones}

\subsection{Comparison with the Krugman's (1991) Model}

Recalling the Krugman (1991) model for target zones of exchange rates, it is:

$$
\begin{gathered}
\mathrm{s}_{\mathrm{t}}=\widehat{F}_{t}+\frac{\alpha}{d t} E_{t}\left\{d s_{\mathrm{t}}\right\}, \\
d \widehat{F}_{t}=v d t+\tilde{\sigma} d \omega_{t}, \\
E_{t} d \mathrm{~s}_{\mathrm{t}}=E_{t} \widehat{F_{t}}+\alpha v, \\
E_{t} d \mathrm{~s}_{\mathrm{t}}=1 / \alpha \int_{t}^{\infty} E_{t}\left\{\widehat{F_{T}}\right\} e^{-(\tau-t) / \alpha} d \tau, \\
E_{t}\left\{d s_{\mathrm{t}}\right\} / d t=s^{\prime}\left(\widehat{F}_{t}\right) v+s^{\prime \prime}\left(\widehat{F}_{t}\right) \tilde{\sigma}^{2} / 2, \\
s(\widehat{F})=\widehat{F}+\alpha s^{\prime}\left(\widehat{F_{t}}\right) v+\alpha s^{\prime \prime}\left(\widehat{F}_{t}\right) \tilde{\sigma}^{2} / 2, \\
s(\widehat{F})=\widehat{F}+\alpha v+\mathrm{A}_{1} e^{\lambda_{1} \hat{F}}+\mathrm{A}_{2} e^{\lambda_{2} \hat{F}} .
\end{gathered}
$$

Where $\widehat{F}_{t}$ is the fundamental variable that determines the exchange rates. $\tilde{\sigma}, \alpha, v, \mathrm{~A}_{1}, \mathrm{~A}_{2}, \lambda_{1}$ and $\lambda_{2}$ are constant parameters, and $\omega_{t}$ is the standard Brownian Motion; $s_{t}$ is the same as in our model. Based on 
Proposition 3.1, we can easily obtain the main equations (46) and (47).

Taking $E_{t}$ in both sides of SDE of exchange rates in Proposition 3.1 and comparing with (46), we get:

$$
\widehat{F_{t}}=-F_{t} / \rho, \quad \alpha=1 / \rho \text {. }
$$

According to (17), we have

$$
\mathrm{F}_{\mathrm{t}}=\hat{\beta} \mathrm{p}_{\mathrm{t}}+\hat{\gamma} m_{t}^{d}+\hat{\theta} y_{t}^{*}+\hat{\lambda} p_{t}^{*}+\hat{\phi} u+\hat{\psi}_{y} \mathrm{E}_{\mathrm{t}} \varepsilon_{y, t}+\widehat{\psi}_{m} \mathrm{E}_{\mathrm{t}} \varepsilon_{m, t}-\psi_{f} \mathrm{f}_{\mathrm{t}},
$$

Therefore,

$$
\mathrm{dF}_{\mathrm{t}}=\hat{\beta} \mathrm{dp}_{\mathrm{t}}+\hat{\gamma} d m_{t}^{d}+\hat{\theta} d y_{t}^{*}+\hat{\lambda} d p_{t}^{*}+\widehat{\psi}_{y} d \mathrm{E}_{\mathrm{t}} \varepsilon_{y, t}+\widehat{\psi}_{m} \mathrm{dE}_{\mathrm{t}} \varepsilon_{m, t}-\psi_{f} d \mathrm{f}_{\mathrm{t}} .
$$

Then, from equations (3) and (14), and the hypothesis (1) and (3), we have

$$
\begin{gathered}
v=-1 / \rho\left\{\theta_{p} \hat{\beta}\left(y_{\mathrm{t}}-y_{t}^{F}\right)+\hat{\gamma} d m_{t}^{d} / d t+\hat{\lambda} d p_{t}^{*} / d t+\hat{\theta} d y_{t}^{*} / d t\right. \\
\left.-\hat{\psi}_{y} \psi_{y} d \mathrm{E}_{\mathrm{t}} \varepsilon_{y, t} / d t-\hat{\psi}_{m} \psi_{m} \mathrm{dE}_{\mathrm{t}} \varepsilon_{m, t} / d t+\psi_{f}^{2} \mathrm{f}_{\mathrm{t}}\right\}, \\
\tilde{\sigma}^{2}=1 / \rho^{2}\left\{\hat{\beta}^{2}\left(\sigma_{p, t}^{2}+\sigma_{f, t}^{2}\right)+\psi^{2} \sigma_{f, t}^{2},\right.
\end{gathered}
$$

where $y_{\mathrm{t}}$ and $y_{t}^{F}$ are expressed by formulas (31) and (43) in Proposition 3.2.

Comparing with Krugman's (1991) model which studies the conditional expectation of $s_{\mathrm{t}}$ with the constant $v$, $v$ in our model is obviously linearly dependent on $s_{\mathrm{t}}$ and the noneconomic factor $\mathrm{f}_{\mathrm{t}}$. Krugman's (1991) model is our special case, if we set $v$ constant.

\subsection{Probabilities That Exchange Rates Reach Boundaries, and the Time They Stay in the Target Zones}

If the exchange rates can maintain in a target zone during a defnite time period, the relative stable exchange rates will improve the international trade and investment. It would be very useful for fiscal policy if we know the probabilities that the exchange rates reach the boundaries of the target zones for the first time and the average time the exchange rates remain in the target zones.

To obtain the close-form solution to these questions, we make the following assumption to simplify our model:

\section{(H) $\mathrm{F}_{\mathrm{t}}$ and $\widehat{\sigma}_{t}$ are constant in the short run.}

Denoting the target zone of the exchange rates by $\left[\mathrm{s}_{l}, \mathrm{~s}_{u}\right]$, no loss of generality, we assume that $0<s_{l}<\mathrm{s}_{0}<$ $\mathrm{s}_{u}$. We will discuss the properties of the target zone of exchange rates in the following subsections.

\subsubsection{Regular Properties of the Target Zone Boundaries}

As a target zone $\left[s_{l}, s_{u}\right]$, the basic condition it must satisfy is that the exchange rates can come back the target zone in a finite time period if they go outside of the zone. This means that according to the theory of SDE in probability theory, $s_{l}$ and $s_{u}$ should be the regular boundary points of the process $\left(s_{t}\right)_{t \geq 0}$ (for the definition, see Revuz and Yor (1991)). That is to say that

$$
\begin{aligned}
& \mathrm{k}\left(\mathrm{s}_{u}\right)<\infty, m\left[\mathrm{~s}_{0}, \mathrm{~s}_{u}\right]<\infty, \\
& \mathrm{k}\left(\mathrm{s}_{l}\right)<\infty, m\left[\mathrm{~s}_{l}, \mathrm{~s}_{0}\right]<\infty \text {, }
\end{aligned}
$$

where

$$
\begin{gathered}
\mathrm{k}(\mathrm{x})=\int_{\mathrm{s}_{0}}^{\mathrm{x}} \int_{\mathrm{s}_{0}}^{\mathrm{y}} \mathrm{m}(\mathrm{dz}) \mathrm{s}^{*}(\mathrm{dy}), \\
\mathrm{m}(\Gamma)=\int_{\Gamma} 2 / \widehat{\sigma}^{2}(\mathrm{x}) \mathrm{s}^{*}(\mathrm{x}) \mathrm{dx}, \Gamma \in \mathrm{B}\left(\left(\left[\begin{array}{ll}
\mathrm{s}_{l}, & \left.\left.\mathrm{~s}_{u}\right)\right),
\end{array}\right.\right.\right.
\end{gathered}
$$

where $\mathrm{m}(\cdot)$ is the so-called Feller standard measure of the process $\left(\mathrm{s}_{\mathrm{t}}\right)$, and

$$
s^{*}(x)=\int_{s_{0}}^{x} \exp \left\{-\int_{s_{0}}^{y} 2(F(\hat{x})+\rho \hat{x}) / \widehat{\sigma}^{2}(\hat{x}) d \hat{x}\right\} d y,
$$

which is the so-called Feller natural scale of the process $\left(s_{t}\right)$.

According to Proposition 3.1 and the hypothesis $(H)$

$$
\mathrm{ds}_{\mathrm{t}}=\left(F+\rho \mathrm{s}_{\mathrm{t}}\right) d t+\hat{\sigma} d z_{s, t}
$$

we find that

$$
\begin{aligned}
\mathrm{s}^{*}(\mathrm{x}) & =\int_{\mathrm{s}_{0}}^{\mathrm{x}}\left\{\exp \left\{-\int_{\mathrm{s}_{0}}^{\mathrm{y}} 2(\mathrm{~F}+\rho \mathrm{u}) / \widehat{\sigma}^{2} \mathrm{du}\right\} \mathrm{dy},\right. \\
& =\exp \left(2 \mathrm{~F} \mathrm{~s}_{0} / \widehat{\sigma}^{2}+s_{0}^{2} \rho / \widehat{\sigma}^{2}\right) \int_{\mathrm{s}_{0}}^{\mathrm{x}} \exp \left\{-\rho \mathrm{y}^{2} / \widehat{\sigma}^{2}-2 F y / \widehat{\sigma}^{2}\right\} d y .
\end{aligned}
$$

It is easy to see that,

$$
\mathrm{k}\left(\mathrm{s}_{u}\right)<\infty, m\left[\mathrm{~s}_{0}, \mathrm{~s}_{u}\right]<\infty,
$$




$$
\mathrm{k}\left(\mathrm{s}_{l}\right)<\infty, m\left[\mathrm{~s}_{l}, \mathrm{~s}_{0}\right]<\infty .
$$

Therefore, $s_{l}$ and $s_{u}$ are regular boundary points of the process $\left(s_{t}\right)$.

\subsubsection{Probabilities That Exchange Rates Reach Boundaries for the First Time}

We will calculate the probabilities that the nominal exchange rates $s_{t}$ reach the up-boundary $s_{u}$ and the low-boundary $s_{l}$ of the target zone for the first time, respectively. It follows the boundary theory of SDE in probability theory (see Revuz and Yor (1991)) that

$$
\begin{gathered}
\mathrm{I}_{l}=P\left(\mathrm{~s}_{\tau\left[\mathrm{s}_{l}, \mathrm{~s}_{u}\right]}=\mathrm{s}_{l}\right)=\left[\mathrm{s}^{*}\left(\mathrm{~s}_{u}\right)-\mathrm{s}^{*}\left(\mathrm{~s}_{0}\right)\right] /\left[\mathrm{s}^{*}\left(\mathrm{~s}_{u}\right)-\mathrm{s}^{*}\left(\mathrm{~s}_{l}\right)\right], \\
\mathrm{I}_{u}=P\left(\mathrm{~s}_{\tau\left[\mathrm{s}_{l}, \mathrm{~s}_{u}\right]}=\mathrm{s}_{u}\right)=\left[\mathrm{s}^{*}\left(\mathrm{~s}_{0}\right)-\mathrm{s}^{*}\left(\mathrm{~s}_{l}\right)\right] /\left[\mathrm{s}^{*}\left(\mathrm{~s}_{u}\right)-\mathrm{s}^{*}\left(\mathrm{~s}_{l}\right)\right],
\end{gathered}
$$

where

$$
\tau\left[\mathrm{s}_{l}, \mathrm{~s}_{u}\right]=\inf \left\{t>0: \mathrm{s}_{t}=\mathrm{s}_{l} \text {, or } \mathrm{s}_{t}=\mathrm{s}_{u}\right\}
$$

is the time that the exchange rates reach the boundaries of the target zone for the first time. Then $\mathrm{I}_{l}$ and $\mathrm{I}_{u}$ are the probabilities that the nominal exchange rates reach $s_{l}$ and $s_{u}$ for the first time respectively.

From equations (56) and (57), we have

Set

$$
\mathrm{I}_{l}=\int_{s_{0}}^{s_{u}} \exp \left(-\rho \mathrm{y}^{2} / \widehat{\sigma}^{2}-2 F y / \widehat{\sigma}^{2}\right) \mathrm{dy} / \int_{s_{l}}^{s_{u}} \exp \left(-\rho \mathrm{y}^{2} / \hat{\sigma}^{2}-2 F y / \hat{\sigma}^{2}\right) \mathrm{dy} .
$$

$$
\omega(\mathrm{y})=-2 F y / \widehat{\sigma}^{2}-\rho \mathrm{y}^{2} / \widehat{\sigma}^{2},
$$

then

$$
\mathrm{I}_{l} \cdot \int_{s_{l}}^{s_{u}} \mathrm{e}^{\omega(\mathrm{y})} \mathrm{dy}=\int_{\mathrm{s}_{0}}^{s_{u}} \mathrm{e}^{\omega(\mathrm{y})} \mathrm{dy}
$$

Differentiating for the fundamental $\mathrm{F}$, we get

Obviously,

$$
\int_{s_{l}}^{s_{u}} e^{\omega(y)} d y / \int_{s_{0}}^{s_{u}} e^{\omega(y)} d y I_{F}^{\prime}=2 / \widehat{\sigma}^{2}\left[\int_{s_{l}}^{s_{u}} \mathrm{ye}^{\omega(\mathrm{y})} \mathrm{dy} / \int_{s_{l}}^{s_{u}} \mathrm{e}^{\omega(\mathrm{y})} \mathrm{dy}-\int_{s_{0}}^{s_{u}} \mathrm{ye}^{\omega(\mathrm{y})} \mathrm{dy} / \int_{s_{0}}^{s_{u}} \mathrm{e}^{\omega(\mathrm{y})} \mathrm{dy}\right] .
$$

Set $\mathrm{J}_{x}=\int_{x}^{\mathrm{s}_{u}} \mathrm{e}^{\omega(\mathrm{y})} \mathrm{ydy} / \int_{x}^{\mathrm{s}_{u}} \mathrm{e}^{\omega(\mathrm{y})} \mathrm{dy}$, then

$$
\int_{s_{l}}^{s_{u}} e^{\omega(y)} d y>0 \text { and } \int_{s_{0}}^{s_{u}} e^{\omega(y)} d y>0 .
$$

$$
J_{x}^{\prime}=\mathrm{e}^{\omega(\mathrm{x})} /\left(\int_{x}^{s_{u}} \mathrm{e}^{\omega(\mathrm{y})} \mathrm{dy}\right)^{2}\left[\int_{x}^{s_{u}} \mathrm{e}^{\omega(\mathrm{y})} \mathrm{ydy}-\mathrm{x} \int_{x}^{s_{u}} \mathrm{e}^{\omega(\mathrm{y})} \mathrm{dy}\right]>0 .
$$

Because $\mathrm{s}_{l}<\mathrm{s}_{0}$, we have $\mathrm{J}_{\mathrm{s}_{l}}<\mathrm{J}_{\mathrm{s}_{0}}$ and

$$
\left(\mathrm{I}_{l}\right)_{F}^{\prime}<0
$$

Similarly, differentiating for $\rho$, we can prove that

$$
\left(\mathrm{I}_{l}\right)_{\rho}^{\prime}<0
$$

Using the same method, it is easy to prove that:

$$
\left(\mathrm{I}_{u}\right)_{F}^{\prime}>0,\left(\mathrm{I}_{u}\right)_{\rho}^{\prime}>0 .
$$

Then we have following proposition for the properties of the probabilities.

Proposition 3. The better (worse) the economic fundamental, the lower (higher) the probability of the exchange rates reaching the low-boundary/up-boundary of the target zone. Increasing the elasticity of the premium rate of exchange rates will decrease/increase the probability that the exchange rates reach the low-boundary/up-boundary of the target zone.

Remark: In recent years, researchers have paid more attention to effects on the changes in exchange rates stemming from the risk (i.e., the standard deviation of shock) of the exchange rates and the non-economic factor. Using equations (17)-(19) along with (20)-(30), and (58)-(60), we can analyze these effects in the following sections.

4.2.3 The Mean Time That the Exchange Rates Maintain in the Target Zones

For any $r_{1}, r_{2}$ such that $s_{l} \leq r_{1}<s_{0}<r_{2} \leq s_{u}$, we set

$$
\tau\left[\mathrm{r}_{1}, \mathrm{r}_{2}\right]=\inf \left\{t>0: \mathrm{s}_{t}=\mathrm{r}_{1} \text {, or } \mathrm{s}_{t}=\mathrm{r}_{2}\right\} .
$$

The $\tau\left[\mathrm{r}_{1}, \mathrm{r}_{2}\right]$ denotes the time of the exchange rates maintaining the interval $\left[\mathrm{r}_{1}, \mathrm{r}_{2}\right]$ of the target zone $\left[\mathrm{s}_{l}, \mathrm{~s}_{u}\right]$. From the the boundary theory of SDE in probability theory (see Revuz and Yor (1991)), the mean value of $\tau\left[r_{1}, r_{2}\right]$ is 
where

$$
\mathrm{E}_{0}\left(\tau\left[\mathrm{r}_{1}, \mathrm{r}_{2}\right]\right)=\int_{\mathrm{r}_{1}}^{\mathrm{r}_{2}} \mathrm{G}\left(\mathrm{s}_{0}, \mathrm{y}\right) \mathrm{m}(\mathrm{dy})>0
$$

$$
\begin{aligned}
& \mathrm{G}\left(\mathrm{s}_{0}, \mathrm{y}\right)=\left(\mathrm{s}^{*}\left(\mathrm{~s}_{0}\right)-\mathrm{s}^{*}\left(\mathrm{r}_{1}\right)\right)\left(\mathrm{s}^{*}\left(\mathrm{r}_{2}\right)-\mathrm{s}^{*}(y)\right) / \mathrm{s}^{*}\left(\mathrm{r}_{2}\right)-\mathrm{s}^{*}\left(\mathrm{r}_{1}\right), \text { if } \mathrm{r}_{1} \leq \mathrm{s}_{0}<y \leq \mathrm{r}_{2} \\
& \mathrm{G}\left(\mathrm{s}_{0}, \mathrm{y}\right)=\left(\mathrm{s}^{*}(y)-\mathrm{s}^{*}\left(\mathrm{r}_{1}\right)\right)\left(\mathrm{s}^{*}\left(\mathrm{r}_{2}\right)-\mathrm{s}^{*}\left(\mathrm{~s}_{0}\right)\right) / \mathrm{s}^{*}\left(\mathrm{r}_{2}\right)-\mathrm{s}^{*}\left(\mathrm{r}_{1}\right), \text { if } \mathrm{r}_{1} \leq y<\mathrm{s}_{0} \leq \mathrm{r}_{2} .
\end{aligned}
$$

So, by (55) we obtain

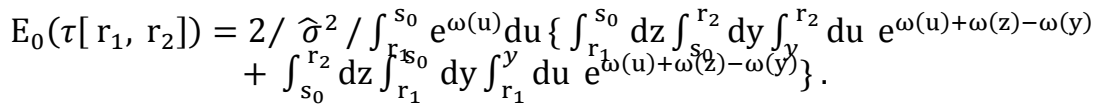

Differentiating for $\hat{\sigma}$, we obtain the following result:

If $F<0$ and $\rho<0$,

(the proof is provided in Appendix C).

$$
\left(\mathrm{E}_{0}\left(\tau\left[\mathrm{r}_{1}, \mathrm{r}_{2}\right]\right)_{\hat{\sigma}^{2}}^{\prime}<0\right.
$$

Remark 3: It is clear that the increasing uncertainty of the exchange rates will shorten the mean time remaining in the interval $\left[r_{1}, r_{2}\right]$, so trying to decrease the uncertainty is a possible method to ensure that the nominal exchange rate $s_{t}$ stays in the target zone.

4.3 The Effects on $\mathrm{I}_{l}$ and $\mathrm{I}_{u}$ from Uncertainty, the Non-Economic Factors, and the Demand for Money

Using a similar method to prove (58), we can get the following relationship:

$$
\begin{aligned}
& \left(\mathrm{I}_{l}\right)_{\widehat{\sigma}^{2}}^{\prime}>0,\left(\mathrm{I}_{u}\right)_{\widehat{\sigma}^{2}}^{\prime}<0(F>0 ; \rho>0) ; \\
& \left(\mathrm{I}_{l}\right)_{\widehat{\sigma}^{2}}<0,\left(\mathrm{I}_{u}\right)_{\widehat{\sigma}^{2}}>0(F<0 ; \rho<0) .
\end{aligned}
$$

Therefore, we can use (19) along with (29), (30), and (63) to analyze the effects on $\mathrm{I}_{l}$ and $\mathrm{I}_{u}$ from economic parameters and the volatilities of all shocks in our model. In particular, we can analyze the behavior of exchange rates when the economy is attacked.

When the economy is attacked, the shock $\varepsilon_{m, t}$ of money, the shock $\varepsilon_{y, t}$ of aggregate demand, the shock of nominal wage, and the shock of the non-economic factor will change frequently, so that the economic policies have to be adjusted accordingly. In a new equilibrium, the economic parameters such as $\eta$, $\xi$ will also be changed. By equations (17)-(19), along with (20)-(30), their changes will affect the values of the fundamental $F$, the elasticity $\rho$ of premium rate, and the uncertainty risk $\widehat{\sigma}^{2}$ of exchange rates. Furthermore, according to (58)-(60), and (63), in the situation $\rho<0$ and $F<0$, if $\widehat{\sigma}^{2}, F$, and $\rho$ increase, then the exchange rates will have larger probability of reaching the up-boundary of the target zone for the first time. Similarly, in the situation of $\rho>0$ and $F>0$, if $\widehat{\sigma}^{2}$, $F$, and $\rho$ increase, then the exchange rates will have smaller probability of reaching the up- boundary of the target zone for the first time. These results indicate that the behavior of the exchange rates is dependent upon the status of $F$ and $\rho$.

We then examine the effect from the non-economic factor $\mathrm{f}_{t}$. By (19), we know that $\mathrm{f}_{t}$ will lead exchange rates to appreciate or depreciate at different levels of the uncertainty risk. Furthermore, by (17) we have

$$
\mathrm{dF} / \mathrm{df}_{t}=-\psi_{f} .
$$

$\psi_{f}$ reflects the degree of the dependence of $F$ on the non-economic factor $\mathrm{f}_{t}$. The greater the mean-reversion $\psi_{f}$, the more important the non-economic factor $\mathrm{f}_{t}$ is. In particular, by (58) and (66) we have

$$
\left(\mathrm{I}_{l}\right)_{f}^{\prime}=-\psi_{f}\left(\mathrm{I}_{l}\right)_{F}^{\prime}>0 \text {, }
$$

which means that the probability of the exchange rates reaching the low boundary of the target zone for the first time will increase if $\left(f_{t}\right)$ increases.

Finally, we discuss the effect of the demand of money. By (17) we have $d F / d m_{t}^{d}=-\hat{\gamma}$. IF $\hat{\gamma}<0$, the increase of demand for money or the monetary expansion will decrease the fundamental $\mathrm{F}$ and the probability $\mathrm{I}_{l}$ will increase. Similarly, if $\hat{\gamma}>0$, and the increase of money demand or a monetary expansion will lead to the increase of fundamental $\mathrm{F}$ and the decrease of the probability $\mathrm{I}_{l}$. Therefore, the demand for money or monetary policy will affect exchange rates directly. Furthermore, the behavior of exchange rates under different monetary policies such as monetary expansion is dependent upon the sign of $\hat{\gamma}$.

\subsection{Analysis of the Effects of Important Macroeconomic Variables on Some Macroeconomic Variables}

From the equation (31) in Proposition 3.2, we know the relationship between the domestic output $y_{\mathrm{t}}$, the nominal 
exchange rate $s_{\mathrm{t}}$, the domestic price level $p_{\mathrm{t}}$, the foreign price level $p_{t}^{*}$, the foreign output $y_{t}^{*}$, and the demand $m_{t}^{d}$ for money. We also note that $\partial y_{\mathrm{t}} / \partial s_{\mathrm{t}}=a_{1}^{y}$. Therefore, if $a_{1}^{y}>0$ and $s_{\mathrm{t}}$ increases, that is to say, if the domestic currency depreciates, then the output $y_{\mathrm{t}}$ will increase. This fact supports that deprecation of domestic currency encourages its export. The lower exchange rates mean that domestic goods will be much more competitive in the international export market. The increasing of the export will motivate the output. But in particular, in case of a collapse of domestic currency, the economy authority will have to adjust its economic policies to avoid the economic crisis. For example, they would take actions to increase the exchange rate $s_{\mathrm{t}}$.

Furthermore, if $a_{1}^{y}>0$, then from (32) and (33) we get $\widetilde{a}>0$, then from (36) - (39), we have $a_{2}^{y}<0, a_{3}^{y}>0$, $a_{4}^{y}>0, a_{5}^{y}>0, a_{6}^{y}>0$, and $a_{7}^{y}<0$. Obviously, a positive $a_{1}^{y}$ means that the demand $m_{t}^{d}$ for money has a positive effect on the output $y_{\mathrm{t}}$. Because $a_{3}^{y}>0, a_{4}^{y}>0$ and $a_{5}^{y}>0$, the foreign economic variables such as the price level $p_{t}^{*}$ and the output $y_{t}^{*}$ also have a positive effect on the domestic output $y_{\mathrm{t}}$. At the same time, if the economy is not in equilibrium at initiation, then the expectation shock $\mathrm{E}_{\mathrm{t}} \varepsilon_{y, t}$ of the aggregate demand and the expectation shock $\mathrm{E}_{\mathrm{t}} \varepsilon_{m, t}$ of the demand of money are not zero. Hence, from (59), if $a_{1}^{y}>0$, then the expectation shock of the aggregate demand will affect output positively, the demand of money on the domestic output is negative. For the domestic price, it is also negative in addition to $a_{2}^{y}<0$.

\section{Conclusion}

Based on Dornbusch (1976)'s model, we establish a dynamic model of exchange rates in a small open economy incorporating macroeconomic variables and their shocks. With the explicit expressions of the fundamental and other factors, we analyze quantitative results of exchange rates.

In practice, the exchange rates cannot always stay in the target zones in the long run, it is good enough for the economy authority to remain the exchange rates in the target zones for a definite time period. Using the theory of SDE in probability theory, we investigate the probabilities that the exchange rates reach the boundaries of the target zones for the first time and the mean time in which the exchange rates remain in the target zone. We find that the probability of exchange rates reaching the upper/lower boundary of the target zone is an increasing function of the fundamental variable and elasticity of premium. The uncertainty of the exchange rate has an important effect on the mean time of exchange rates staying in the target zone. We also analyze the effects from all kinds of variables, such as macroeconomic variables with their shocks, the non-economic factor with its shock, the economic parameters, and the volatilities of shocks.

\section{References}

Bauer, C, P. De Grauwe, \& S. Reitz. (2009). Exchange Rate Dynamics in A Target Zone-A Heterogeneous Expectations Approach. Journal of Economic Dynamics and Control, 33, 329-344. http://dx.doi.org/10.1016/j.jedc.2008.05.008

Beetsma, R. M. W. J., \& F. van der Ploeg. (1998). Macroeconomic Stabilization and Intervention Policy under an Exchange Rate Band. Journal of International Money and Finance, 17, 339-353. http://dx.doi.org/10.1016/S0261-5606(98)00007-2

Beladi, H., \& A. Chakrabarti. (2012). Stochastic Processes and Target Zones Revisited. Economics Letters, 116, 34-36. http://dx.doi.org/10.1016/j.econlet.2011.12.065

Bertola, G., \& R. J. Caballero. (1992). Target Zones and Realignments. American Economic Review, 82, 520-536.

Bertola, G., \& L. Svensson. (1993). Stochastic Devaluation Risk and the Empirical Fit of Target-zone Models. Review of Economic Studies, 60, 689-712. http://dx.doi.org/10.2307/2298131

Christensen, P.O., D. Lando, \& K.R. Miltersen. (1998). State Dependent Realignments in Target Zone Currency Regimes. Review of Derivatives Research, 1, 295-323.

De Jong, F., F.C. Drost, \& B.J.M. Werker. (2001). A Jump-diffusion Model for Exchange Rates in A Target Zone. Statistica Neerlandica, 55, 270-300. http://dx.doi.org/10.1111/1467-9574.00170

Dornbusch, R. (1976). Expectations and exchange rate dynamics. Journal of Political Economics, 84, 1161-1176. http://dx.doi.org/10.1086/260506

Duarte, A. P., Andrade, J. S., \& Duarte, A. (2011). Exchange Rate Target Zones: A Survey of the Literature. Journal of Economic Surveys, 27(2). http://dx.doi.org/10.1111/j.1467-6419.2011.00703.x

Ito, T., \& T. Yabu. (2007). What Prompts Japan to Intervene in the Forex Market? A New Approach to A Reaction Function. Journal of International Money and Finance, 26, 193-212. 
http://dx.doi.org/10.1016/j.jimonfin.2006.12.001

Klein, M. W. (1990). Playing with the Band: Dynamic Effects of Target Zones in an Open Economy. International Economic Review, 31, 757-772. http://dx.doi.org/10.2307/2527014

Krugman, P. R. (1991). Target Zones and Exchange Rate Dynamics. Quarterly Journal of Economics, 106, 669-682. http://dx.doi.org/10.2307/2937922

Lai, C., Fang, C., \& Chang, J. (2008). Volatility Trade-offs in Exchange Rate Target Zones. International Review of Economics and Finance, 17, 366-379. http://dx.doi.org/10.1016/j.iref.2006.10.004

Larsen, K.S., \& M. Sorensen. (2007). Diffusion Models for Exchange Rates in A Target Zone. Mathematical Finance, 17, 295-306. http://dx.doi.org/10.1111/j.1467-9965.2006.00304.x

Lee, H. Y. (2011). Nonlinear Exchange Rate Dynamics under Stochastic Official Intervention. Economic Modelling, 28, 1510-1518. http://dx.doi.org/10.1016/j.econmod.2011.02.024

Miller, M., \& Weller, P. (1991). Exchange rate bands with price inertia. Economic Journal, 101, 1380-1399. http://dx.doi.org/10.2307/2234891

Revuz, D., \& M. Yor. (1991). Continuous Martingales and Brownian Motion. Springer-Verlag, Berlin /Heidelberg /New York. http://dx.doi.org/10.1007/978-3-662-21726-9

Serrat, A. (2000). Exchange Rate Dynamics in a Multilateral Target Zone. Review of Economic Studies, 67, 193-211. http://dx.doi.org/10.1111/1467-937X.00127

Tronzano, M., Z. Psaradakis, \& M. Sola. (2003). Target Zone Credibility and Economic Fundamentals. Economic Modelling, 20, 791-807. http://dx.doi.org/10.1016/S0264-9993(02)00009-3

Appendix

A. The Proof of Proposition 3.1:

Proof 1 From the formulas (7), (14) and (16), we have

$$
r_{\mathrm{t}}=\mathrm{i}_{\mathrm{t}}-\pi\left[u+\delta\left(\mathrm{s}_{\mathrm{t}}-\mathrm{p}_{\mathrm{t}}\right)+(\gamma-1) \mathrm{y}_{\mathrm{t}}-\sigma \mathrm{i}_{\mathrm{t}}\right] .
$$

Taking the conditional expectation $E_{\mathrm{t}}$ for both sides of equations (1) and (2), we get:

$$
\begin{aligned}
\mathrm{y}_{\mathrm{t}}= & \alpha\left(\mathrm{s}_{\mathrm{t}}+p_{t}^{*}-p_{\mathrm{t}}\right)+\beta y_{t}^{*}-\tilde{\delta} \mathrm{r}_{\mathrm{t}}+E_{\mathrm{t}} \varepsilon_{y, t}, \\
& m_{t}^{d}-p_{\mathrm{t}}=\phi \mathrm{y}_{\mathrm{t}}-\lambda \mathrm{i}_{\mathrm{t}}+\mathrm{E}_{\mathrm{t}} \varepsilon_{y, t} .
\end{aligned}
$$

Then we have

$$
\begin{gathered}
\mathrm{y}_{\mathrm{t}}=\alpha\left(\mathrm{s}_{\mathrm{t}}+p_{t}^{*}-p_{\mathrm{t}}\right)+\beta y_{t}^{*}-\tilde{\delta} \mathrm{i}_{\mathrm{t}} \\
+\pi \tilde{\delta}\left[u+\delta\left(\mathrm{s}_{\mathrm{t}}-\mathrm{p}_{\mathrm{t}}\right)+(\gamma-1) \mathrm{y}_{\mathrm{t}}-\sigma \mathrm{i}_{\mathrm{t}}\right]+\mathrm{E}_{\mathrm{t}} \varepsilon_{y, t} .
\end{gathered}
$$

So we have

$$
[1-\pi \tilde{\delta}(\gamma-1)] \mathrm{y}_{\mathrm{t}}=(\alpha+\pi \tilde{\delta} \delta)\left(\mathrm{s}_{\mathrm{t}}-\mathrm{p}_{\mathrm{t}}\right)-(\tilde{\delta}+\pi \tilde{\delta} \sigma) \mathrm{i}_{\mathrm{t}}+\alpha p_{t}^{*}+\beta y_{t}^{*}+\pi \tilde{\delta} u+\mathrm{E}_{\mathrm{t}} \varepsilon_{y, t}
$$

Taking this expression into (68) we obtain

$$
\begin{gathered}
{[\lambda(1-\pi \tilde{\delta} \gamma+\pi \tilde{\delta})+\phi \tilde{\delta}(1+\pi \sigma)] \mathrm{i}_{\mathrm{t}}=\phi(\alpha+\pi \tilde{\delta} \delta)+\phi \alpha p_{t}^{*}+[(1-\pi \tilde{\delta} \gamma+\pi \tilde{\delta})-\phi(\alpha+\pi \tilde{\delta} \delta)] \mathrm{p}_{\mathrm{t}}} \\
+(\pi \tilde{\delta} \gamma-\pi \tilde{\delta}-1) m_{t}^{d}+\phi \beta y_{t}^{*}+\phi \pi \tilde{\delta} u_{\mathrm{t}}+(1-\pi \tilde{\delta} \gamma+\pi \tilde{\delta}) \mathrm{E}_{\mathrm{t}} \varepsilon_{m, t}+\phi \mathrm{E}_{\mathrm{t}} \varepsilon_{y, t}
\end{gathered}
$$

Set

$$
a=1 /[\lambda(1-\pi \tilde{\delta} \gamma+\pi \tilde{\delta})+\phi \tilde{\delta}(1+\pi \sigma)]
$$

then it implies

$$
\begin{aligned}
\mathrm{i}_{\mathrm{t}}= & a \phi(\alpha+\pi \tilde{\delta} \delta) \mathrm{s}_{\mathrm{t}}+a[1-\pi \tilde{\delta} \gamma+\pi \tilde{\delta}-\phi(\alpha+\pi \tilde{\delta} \delta)] \mathrm{p}_{\mathrm{t}}+a(\pi \tilde{\delta} \gamma-\pi \tilde{\delta}-1) m_{t}^{d}+a \phi \alpha p_{t}^{*} \\
& +a \phi \beta y_{t}^{*}+a \phi \pi \tilde{\delta} u_{\mathrm{t}}+a(1-\pi \tilde{\delta} \gamma+\pi \tilde{\delta}) \mathrm{E}_{\mathrm{t}} \varepsilon_{m, t}+a \phi \mathrm{E}_{\mathrm{t}} \varepsilon_{y, t} .
\end{aligned}
$$

From the equations (8), (11) and (13) we get

$$
\begin{aligned}
\mathrm{E}_{\mathrm{t}} d s_{\mathrm{t}} / d t= & \left(1+1 / \widetilde{\mathrm{E}_{\mathrm{s}}}\right) \mathrm{i}_{\mathrm{t}}-i_{t}^{*}-\psi_{f} \mathrm{f}_{\mathrm{t}}=\left[1 / \widetilde{\mathrm{E}_{\mathrm{s}}}+\pi \lambda(\gamma-1) / \phi-\pi \sigma\right] \mathrm{i}_{\mathrm{t}}+\pi \delta \mathrm{s}_{\mathrm{t}} \\
& +\pi \lambda(\gamma-1) / \phi m_{t}^{d}-\pi[\delta+(\gamma-1) / \phi] \mathrm{p}_{\mathrm{t}}-\psi_{f} \mathrm{f}_{\mathrm{t}}+\pi u-\pi(\gamma-1) / \phi \mathrm{E}_{\mathrm{t}} \varepsilon_{m, t}
\end{aligned}
$$

Set 


$$
\begin{gathered}
\hat{\alpha}=a \phi(\alpha+\pi \delta \tilde{\delta})\left[1 / \widetilde{\mathrm{E}_{\mathrm{s}}}+\pi \lambda(\gamma-1) / \phi-\pi \sigma\right]+\pi \delta, \\
\left.\hat{\beta}=a[1-\pi \gamma \tilde{\delta}+\pi \delta-\phi(\alpha+\pi \delta \tilde{\delta})]\left[1 / \widetilde{\mathrm{E}_{\mathrm{s}}}+\pi \lambda(\gamma-1) / \phi-\pi \sigma\right]-[\pi \delta+(\gamma-1) / \phi)\right], \\
\hat{\gamma}=a(\pi \gamma \tilde{\delta}-\pi \tilde{\delta}-1)\left[1 / \widetilde{\mathrm{E}_{\mathrm{s}}}+\pi \lambda(\gamma-1) / \phi-\pi(\gamma-1) / \phi\right], \\
\hat{\lambda}=a \phi \alpha\left[1 / \widetilde{\mathrm{E}_{\mathrm{s}}}+\pi \lambda(\gamma-1) / \phi-\pi \sigma\right], \\
\hat{\theta}=a \phi \beta\left[1 / \widetilde{\mathrm{E}_{\mathrm{s}}}+\pi \lambda(\gamma-1) / \phi-\pi \sigma\right]+\pi, \\
\hat{\phi}=a \phi \pi \tilde{\delta}\left[1 / \widetilde{\mathrm{E}_{\mathrm{s}}}+\pi \lambda(\gamma-1) / \phi-\pi \sigma\right]+\pi, \\
\hat{\psi}_{y}=a \phi\left[1 / \widetilde{\mathrm{E}_{\mathrm{s}}}+\pi \lambda(\gamma-1) / \phi-\pi \sigma\right], \\
\hat{\psi}_{m}=a(1-\pi \gamma \tilde{\delta}+\pi \tilde{\delta})\left[1 / \widetilde{\mathrm{E}_{\mathrm{s}}}+\pi \lambda(\gamma-1) / \phi-\pi \sigma\right]-\pi(\gamma-1) / \phi,
\end{gathered}
$$

and taking (70) into (69) we know the $\mathrm{F}_{\mathrm{t}}$ and $\rho$ as follows:

$$
\begin{gathered}
\mathrm{F}_{\mathrm{t}}=\hat{\beta} \mathrm{p}_{\mathrm{t}}+\hat{\gamma} m_{t}^{d}+\hat{\theta} y_{t}^{*}+\hat{\lambda} p_{t}^{*}+\hat{\phi} u-\psi_{f} \mathrm{f}_{\mathrm{t}}+\hat{\psi}_{y} \mathrm{E}_{\mathrm{t}} \varepsilon_{y, t}+\hat{\psi}_{m} \mathrm{E}_{\mathrm{t}} \varepsilon_{m, t}, \\
\rho=\hat{\alpha} .
\end{gathered}
$$

In the following we calculate $\hat{\sigma}_{\mathrm{t}}$.

Differentiating the equations (2) and (3), we obtain that

$$
\begin{gathered}
\mathrm{dy}_{\mathrm{t}}=\alpha d \mathrm{~s}_{\mathrm{t}}+\alpha d p_{t}^{*}-\alpha d p_{\mathrm{t}}+\beta d y_{t}^{*}-\widetilde{\delta d} \mathrm{r}_{\mathrm{t}}+d \varepsilon_{y, t} \\
d m_{t}^{d}-d p_{\mathrm{t}}=\emptyset \mathrm{dy}_{\mathrm{t}}-\lambda d \mathrm{i}_{\mathrm{t}}+d \varepsilon_{m, t}
\end{gathered}
$$

Note that by (14) and (16)

$$
r_{\mathrm{t}}=\mathrm{i}_{\mathrm{t}}-\pi\left[\delta\left(\mathrm{s}_{\mathrm{t}}-\mathrm{p}_{\mathrm{t}}\right)+(\gamma-1) \mathrm{y}_{\mathrm{t}}-\sigma \mathrm{i}_{\mathrm{t}}+u\right]
$$

Differentiating it and according to the equation (69) along with the hypothesis (1), we get

$$
\begin{gathered}
d r_{\mathrm{t}}=(1+\pi \sigma) d \mathrm{i}_{\mathrm{t}}-\pi \delta d \mathrm{~s}_{\mathrm{t}}+\pi \delta d \mathrm{p}_{\mathrm{t}}-\pi(\gamma-1) d \mathrm{y}_{\mathrm{t}}, \\
d i_{\mathrm{t}} \sim a \phi(\alpha+\pi \tilde{\delta} \delta) d \mathrm{~s}_{\mathrm{t}}+a[1-\pi \tilde{\delta} \gamma+\pi \tilde{\delta}-\phi(\alpha+\pi \tilde{\delta} \delta)] d \mathrm{p}_{\mathrm{t}},
\end{gathered}
$$

where and since then " " means that the terms are equal up to the differential of a finite variant process. So again by the hypothesis (1) we obtain:

$$
\begin{gathered}
\phi(\alpha+\pi \tilde{\delta} \delta) d \mathrm{~s}_{\mathrm{t}} \sim[\lambda(1-\pi \tilde{\delta} \gamma+\pi \tilde{\delta})+\phi \tilde{\delta}(1+\pi \sigma)] d \mathrm{i}_{\mathrm{t}} \\
+[\phi(\alpha+\pi \tilde{\delta} \delta)+\pi \tilde{\delta}(\gamma-1)-1] d \mathrm{p}_{\mathrm{t}}+[\pi \tilde{\delta}(\gamma-1)-1] d \varepsilon_{m, t}-\emptyset d \varepsilon_{y, t},
\end{gathered}
$$

Using the above expression of dit we get

$$
\begin{aligned}
& \{\phi(\alpha+\pi \tilde{\delta} \delta)-a \phi(\alpha+\pi \tilde{\delta} \delta)[\lambda(1-\pi \tilde{\delta} \gamma+\pi \tilde{\delta})+\phi \tilde{\delta}(1+\pi \sigma)]\} d \mathrm{~s}_{\mathrm{t}} \\
\sim & \{[\phi(\alpha+\pi \tilde{\delta} \delta)-1+\pi \tilde{\delta}(\gamma-1)]+a[\lambda(1-\pi \tilde{\delta} \gamma+\pi \tilde{\delta})+\phi \tilde{\delta}(1+\pi \sigma)] \\
& {[1-\pi \tilde{\delta} \gamma+\pi \tilde{\delta}-\phi(\alpha+\pi \tilde{\delta} \delta)]\} d \mathrm{p}_{\mathrm{t}}+(\pi \tilde{\delta} \gamma-\pi \tilde{\delta}-1) d \varepsilon_{m, t}-\emptyset d \varepsilon_{y, t} . }
\end{aligned}
$$

It follows from the above fact and the equations (3), (4), (12) that

$$
\xi d s_{\mathrm{t}} \sim \eta\left(\sigma_{p, t} d z_{p, t}+\sigma_{f, t} d z_{f, t}\right)-\sigma_{m, t}(1+\pi \tilde{\delta} \gamma) d z_{m, t}-\phi \sigma_{y, t} d z_{y, t},
$$

where

$$
\begin{gathered}
\xi=\phi(\alpha+\pi \tilde{\delta} \delta)[1-a \lambda(1-\pi \tilde{\delta} \gamma+\pi \tilde{\delta})+a \phi \tilde{\delta}(1+\pi \sigma)], \\
\eta=\phi(\alpha+\pi \tilde{\delta} \delta)-1+\pi \tilde{\delta}(\gamma-1)+a[\lambda(1-\pi \tilde{\delta} \gamma+\pi \tilde{\delta})+\phi \tilde{\delta}(1+\pi \sigma)][1-\pi \tilde{\delta} \gamma+\pi \tilde{\delta}-\phi(\alpha+\pi \tilde{\delta} \delta)] .
\end{gathered}
$$

According to Ito's formula and the hypothesis (4) we have

So we obtain that

$$
\xi^{2} \mathrm{E}_{\mathrm{t}}\left(d \mathrm{~s}_{\mathrm{t}}\right)^{2} / d t=\eta^{2}\left(\sigma_{p, t}^{2}+\sigma_{f, t}^{2}\right)+(\pi \tilde{\delta} \gamma-\pi \tilde{\delta}-1)^{2} \sigma_{m, t}^{2}+\phi^{2} \sigma_{y, t}^{2} .
$$

$$
\hat{\sigma}_{\mathrm{t}}^{2}=\mathrm{E}_{\mathrm{t}}\left(d \mathrm{~s}_{\mathrm{t}}\right)^{2} / d t=(\eta / \xi)^{2}\left(\sigma_{p, t}^{2}+\sigma_{f, t}^{2}\right)+(\pi \tilde{\delta} \gamma-\pi \tilde{\delta}-1)^{2} / \xi^{2} \sigma_{m, t}^{2}+(\phi / \xi)^{2} \sigma_{y, t}^{2} .
$$

We completes the proof of Proposition 3.1. 
B. Some expressions of Parameters in Proposition 3.2:

$$
\begin{aligned}
& b_{1}^{i}=a \phi(\alpha+\pi \tilde{\delta} \delta), \quad b_{2}^{i}=a[1-\pi \tilde{\delta} \gamma+\pi \tilde{\delta}-\phi(\alpha+\pi \tilde{\delta} \delta)], \quad b_{3}^{i}=a(\pi \tilde{\delta} \gamma-\pi \tilde{\delta}-1), \\
& b_{4}^{i}=a \phi \alpha, \quad b_{5}^{i}=a \phi \beta, \quad b_{6}^{i}=a \phi, \quad b_{7}^{i}=a(1-\pi \tilde{\delta} \gamma+\pi \tilde{\delta}), \quad u^{i}=a \phi \pi \tilde{\delta} u \\
& c_{1}^{s}=\left[a_{1}^{y} \pi(\gamma-1)-\pi \sigma b_{1}^{i}+\pi \sigma+\theta\right] / \theta, \quad c_{2}^{s}=\left[a_{2}^{y} \pi(\gamma-1)-\pi \delta-\pi \sigma b_{2}^{i}\right] / \theta, \\
& c_{3}^{s}=\left[a_{3}^{y} \pi(\gamma-1)-\pi \sigma b_{3}^{i}\right] / \theta, \quad c_{4}^{s}=\left[a_{4}^{y} \pi(\gamma-1)-\pi \sigma b_{4}^{i}\right] / \theta, c_{5}^{s}=\left[a_{5}^{y} \pi(\gamma-1)-\pi \sigma b_{5}^{i}\right] / \theta \text {, } \\
& c_{6}^{s}=\left[a_{6}^{y} \pi(\gamma-1)-\pi \sigma b_{6}^{i}\right] / \theta, \quad c_{7}^{s}=\left[a_{7}^{y} \pi(\gamma-1)-\pi \sigma b_{7}^{i}\right] / \theta, u^{s}=\left[u^{y} \pi(\gamma-1)-\pi \sigma u^{i}+\pi u\right] / \theta \text {, } \\
& d_{1}^{F}=\left[\theta_{p} a_{1}^{y}+\theta c_{1}^{s}-\theta\right] / \theta_{p}, \quad d_{2}^{F}=\left[\theta_{p} a_{2}^{y}+\theta c_{2}^{s}\right] / \theta_{p}, \quad d_{3}^{F}=\left[\theta_{p} a_{3}^{y}+\theta c_{3}^{s}\right] / \theta_{p}, d_{4}^{F}=\left[\theta_{p} a_{4}^{y}+\theta c_{4}^{s}\right] / \theta_{p}, \\
& d_{5}^{F}=\left[\theta_{p} a_{5}^{y}+\theta c_{5}^{s}\right] / \theta_{p}, \quad d_{6}^{F}=\left[\theta_{p} a_{6}^{y}+\theta c_{6}^{s}\right] / \theta_{p}, \quad d_{7}^{F}=\left[\theta_{p} a_{7}^{y}+\theta c_{7}^{s}\right] / \theta_{p}, u^{F}=\left[\theta_{p} u^{y}+\theta u^{s}\right] / \theta_{p}, \\
& j_{1}^{*}=b_{1}^{i}-\theta c_{1}^{s}+\theta, \quad j_{2}^{*}=b_{2}^{i}-\theta c_{2}^{s}, \quad j_{3}^{*}=b_{3}^{i}-\theta c_{3}^{s}, \quad j_{4}^{*}=b_{4}^{i}-\theta c_{4}^{s} \\
& j_{5}^{*}=b_{5}^{i}-\theta c_{5}^{s}, \quad j_{6}^{*}=b_{6}^{i}-\theta c_{6}^{s}, \quad j_{7}^{*}=b_{7}^{i}-\theta c_{7}^{s}, \quad u^{*}=u^{i}-\theta u^{s}, \\
& k_{1}^{p}=c_{1}^{s}-\left[\sigma j_{1}^{*}+(1-\gamma) d_{1}^{F}\right] / \delta, \quad k_{2}^{p}=c_{2}^{s}-\left[\sigma j_{2}^{*}+(1-\gamma) d_{2}^{F}\right] / \delta, \quad k_{3}^{p}=c_{3}^{s}-\left[\sigma j_{3}^{*}+(1-\gamma) d_{3}^{F}\right] / \delta, \\
& k_{4}^{p}=c_{4}^{s}-\left[\sigma j_{4}^{*}+(1-\gamma) d_{4}^{F}\right] / \delta, \quad k_{5}^{p}=c_{5}^{s}-\left[\sigma j_{5}^{*}+(1-\gamma) d_{5}^{F}\right] / \delta, \quad k_{6}^{p}=c_{6}^{S}-\left[\sigma j_{6}^{*}+(1-\gamma) d_{6}^{F}\right] / \delta, \\
& k_{7}^{p}=c_{7}^{S}-\left[\sigma j_{7}^{*}+(1-\gamma) d_{7}^{F}\right] / \delta, \quad u^{p}=u^{s}-\left[\sigma u^{*}+(1-\gamma) u^{F}-u\right] / \delta .
\end{aligned}
$$

C. the proof of $\left(E_{0}\left(\tau\left[r_{1}, r_{2}\right]\right)_{\widehat{\sigma}^{2}}^{\prime}<0\right.$.

Proof 2 We know that

$$
\begin{aligned}
\left(\mathrm{E}_{0}\left(\tau\left[\mathrm{r}_{1}, \mathrm{r}_{2}\right]\right)_{\widehat{\sigma}^{2}}^{\prime}=-2 / \widehat{\sigma}^{2} \mathrm{E}_{0}\left(\tau\left[\mathrm{r}_{1}, \mathrm{r}_{2}\right]\right)+1 / \widehat{\sigma}^{4} \mathrm{E}_{0}\left(\tau\left[\mathrm{r}_{1}, \mathrm{r}_{2}\right]\right) \int_{\mathrm{r}_{1}}^{\mathrm{r}_{2}} \mathrm{e}^{\omega(\mathrm{u})}\left(2 \mathrm{Fu}+\rho u^{2}\right) \mathrm{du} / \int_{\mathrm{r}_{1}}^{\mathrm{r}_{2}} \mathrm{e}^{\omega(\mathrm{u})} \mathrm{du}\right. \\
+2 / \widehat{\sigma}^{6} / \int_{\mathrm{r}_{1}}^{\mathrm{s}_{0}} \mathrm{e}^{\omega(\mathrm{u})} \mathrm{du}\left\{\int_{\mathrm{r}_{1}}^{\mathrm{s}_{0}} \mathrm{dz} \int_{\mathrm{s}_{0}}^{\mathrm{r}_{2}} \mathrm{dy} \int_{y}^{\mathrm{r}_{2}} \mathrm{du} \mathrm{e}^{\omega(\mathrm{u})+\omega(\mathrm{z})-\omega(\mathrm{y})}\left[2 \mathrm{~F}(\mathrm{u}+\mathrm{z}-\mathrm{y})+\rho\left(u^{2}+z^{2}-y^{2}\right)\right]\right. \\
\left.\quad+\int_{\mathrm{s}_{0}}^{\mathrm{r}_{2}} \mathrm{dz} \int_{\mathrm{r}_{1}}^{\mathrm{s}_{0}} \mathrm{dy} \int_{\mathrm{r}_{1}}^{y} \mathrm{du} \mathrm{e}^{\omega(\mathrm{u})+\omega(\mathrm{z})-\omega(\mathrm{y})}\left[2 \mathrm{~F}(\mathrm{u}+\mathrm{z}-\mathrm{y})+\rho\left(u^{2}+z^{2}-y^{2}\right)\right]\right\} \\
\quad=\mathrm{A}_{1}+\mathrm{A}_{2}+\mathrm{A}_{3}+\mathrm{A}_{4} .
\end{aligned}
$$

Note that in $A_{3}, u>y>z$, so

if $F<0$ and $\rho<0,2 \mathrm{~F}(\mathrm{u}+\mathrm{z}-\mathrm{y})+\rho\left(u^{2}+z^{2}-y^{2}\right)<0$.

We know if $F<0$ and $\rho<0, \mathrm{~A}_{3}<0$

Using the same method, we have if $F<0$ and $\rho<0, \mathrm{~A}_{4}<0$

Evidently, we know

$$
\mathrm{A}_{1}=-2 / \hat{\sigma}^{2} \mathrm{E}_{0}\left(\tau\left[\mathrm{r}_{1}, \mathrm{r}_{2}\right]\right)<0,
$$

If $F<0$ and $\rho<0$,

$$
A_{2}=1 / \widehat{\sigma}^{4} E_{0}\left(\tau\left[r_{1}, r_{2}\right]\right) \int_{r_{1}}^{r_{2}} e^{\omega(u)}\left(2 F u+\rho u^{2}\right) d u / \int_{r_{1}}^{r_{2}} e^{\omega(u)} d u<0
$$

So we know that

If $F<0$ and $\rho<0$,

$$
\left(\mathrm{E}_{0}\left(\tau\left[\mathrm{r}_{1}, \mathrm{r}_{2}\right]\right)_{\widehat{\sigma}^{2}}^{\prime}<0\right.
$$

